\title{
CORRIGENDA
}

\section{RAD18, WRNIP1 and ATMIN promote ATM signalling in response to replication stress}

N Kanu, T Zhang, RA Burrell, A Chakraborty, J Cronshaw, C DaCosta, E Grönroos, HN Pemberton, E Anderton, L Gonzalez,

S Sabbioneda, HD Ulrich, C Swanton and A Behrens

Oncogene (2016) 35, 4020; doi:10.1038/onc.2015.500; published online 27 June 2016

Correction to: Oncogene (2016) 35, 4009-4019; doi:10.1038/ onc.2015.427; published online 9 November 2015

Since the online publication of this article the authors noticed an error in one author's name. C DaCosta has now been corrected.
The authors apologise for any inconvenience caused by this error. This error has now been rectified, and the corrected article appears in this issue. The html and online pdf versions have also been rectified, and now carry the corrected paper.

\section{DNA methylation reactivates $G A D 1$ expression in cancer by preventing CTCF-mediated polycomb repressive complex 2 recruitment}

H Yan, G Tang, H Wang, L Hao, T He, X Sun, AH Ting, A Deng and S Sun

Oncogene (2016) 35, 4020; doi:10.1038/onc.2016.28; published online 27 June 2016

Correction to: Oncogene (2016) 35, 3995-4008; doi:10.1038/ onc.2015.423; published online 9 November 2015

Since the online publication of this article the authors noticed that grant number 81172307 from the National Natural Science Foundation of China had not been included in the Acknowledgements. Grant number 81172307 has now been added.
The authors apologise for any inconvenience caused by this error. This error has now been rectified, and the corrected article appears in this issue. The html and online pdf versions have also been rectified, and now carry the corrected paper. 